$\underline{\text { Case Reports }}$

\title{
Takayasu Arteritis Initially Mimicking Infective Endocarditis
}

Aytekin Alcelik, Sevim Karacay, Ismail Necati Hakyemez, Busra Akin, Serkan Ozturk and Haluk Savli

Deparment of Internal Medicine, Abant Izzet Baysal University, Bolu, Turkey

Correspondance: Dr. Aytekin Alcelik. E-mail: aytekinalcelik@yahoo.com

Competing interests: The authors have declared that no competing interests exist.

Published: September 8, 2011

Received: June 8, 2011

Accepted: August 3, 2011

Mediterr J Hematol Infect Dis 2011, 3: e2011040, DOI 10.4084/MJHID.2011.040

This article is available from: http://www.mjhid.org/article/view/8801

This is an Open Access article distributed under the terms of the Creative Commons Attribution License (http://creativecommons.org/licenses/by/2.0), which permits unrestricted use, distribution, and reproduction in any medium, provided the original work is properly cited.

Takayasu's arteritis (TA) is a chronic inflammatory disease that affects large vessels, predominantly the aorta and its main branches, leading to vessel wall thickening, fibrosis and stenosis. Cardiac and vascular symptoms are also commonly present at disease onset. In TA with thoracic or abdominal involvement, although murmur can be present at physical examination, the pulse difference may be absent. Here, we report a case of TA who initially resembled infective endocarditis and had widespread thoracic murmur.

Introduction: Takayasu's arteritis (TA) is a chronic inflammatory disease that affects large vessels, predominantly the aorta and its main branches, leading to vessel wall thickening, fibrosis and stenosis. The etiology and predisposing factors of TA are so far unknown. The main clinical symptoms and signs are weakness, fever, arthralgia, hypertension, intermittent claudication of the upper or lower limbs, cardiac diseases (cardiac failure, valvular or ischemic heart disease) and impaired renal function. Laboratory findings are non-specific. Treatment of the active disease is primarily based on corticosteroids. ${ }^{1-2}$

Cardiac and vascular symptoms are also commonly present at disease onset. In TA with thoracic or abdominal involvement, although murmur can be present at physical examination, the pulse difference may be absent. ${ }^{3-4}$ Therefore, TA can be misdiagnosed as infective endocarditis because of murmur and fever associated with the active phase of the disease.

Here, we report a case of TA who initially resembled infective endocarditis and had widespread thoracic murmur.

Case: A 30-year-old woman was admitted with the complaint of sore throat and polyarthralgia for five days. The patient also reported headache, dizziness and fever. At presentation, her body temperature was $37.5^{\circ} \mathrm{C}$ and blood pressure in right arm was $180 / 90$ $\mathrm{mmHg}$ and in left arm was $170 / 80 \mathrm{mmHg}$. Physical examination showed widespread thoracic murmur and weak pulses in both arms. Ophthalmoscopic examination was normal. Laboratory findings were as follows: hemoglobin was $12.2 \mathrm{~g} / \mathrm{dL}$, hematocrit was $36 \%$, white blood cell count was $12,500 / \mathrm{mm}^{3}$, platelet count was $296,000 / \mathrm{mm}^{3}$ and mean corpuscular volume was 80 femtoliter. Fasting glucose level, calcium, albumin, urea and creatinine levels were within the normal range. Sedimentation rate was $31 \mathrm{~mm}, \mathrm{C}$ reactive protein (CRP) was $52 \mathrm{mg} / \mathrm{dL}$ (range from 0 $3.19 \mathrm{mg} / \mathrm{dL}$ ). Urine examination was normal. Throat culture did not yield beta hemolytic Streptococci. Telecardiography (Figure1) and electrocardiogram 


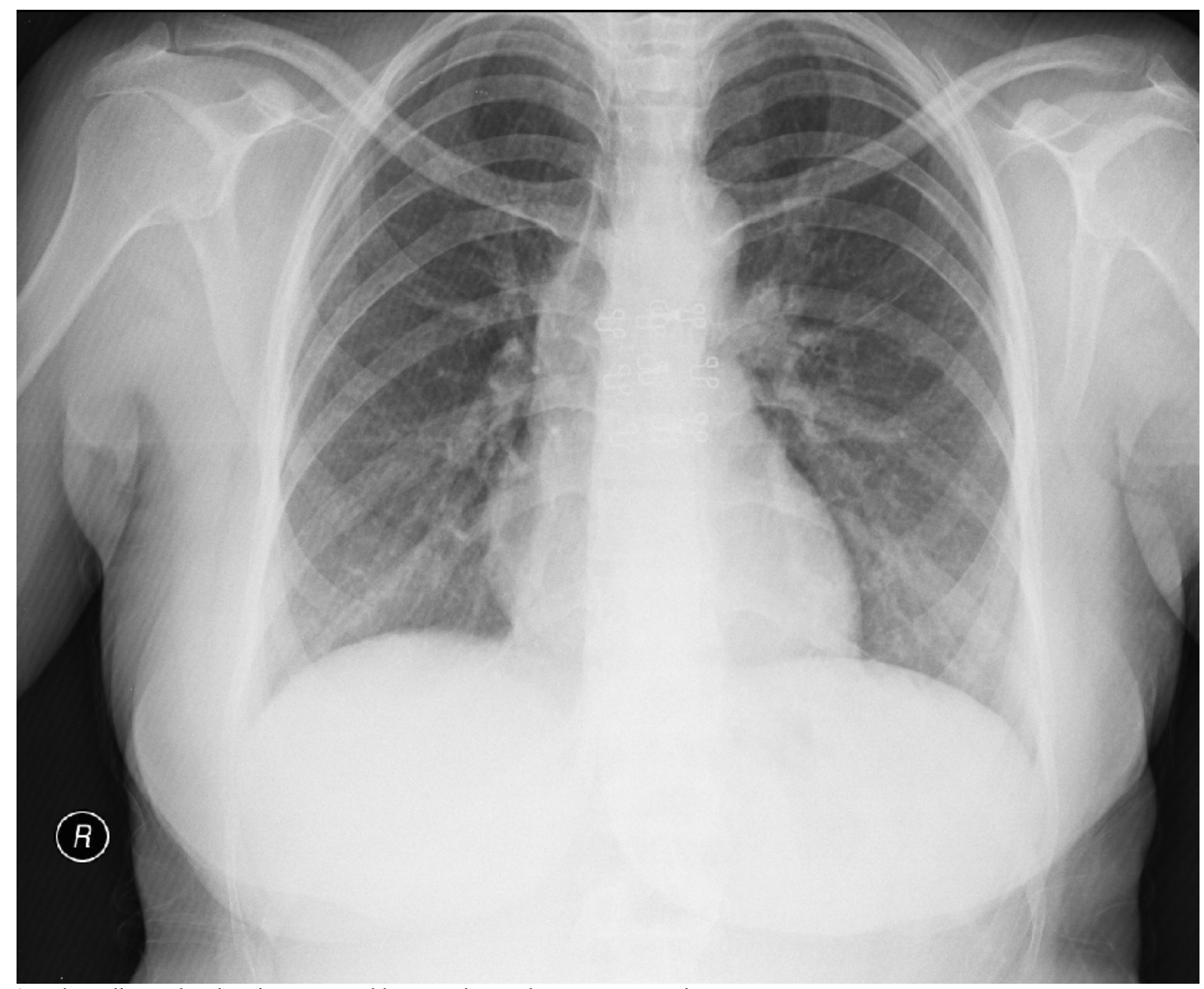

Figure 1. Telecardiography showing a normal heart and no pulmonary congestion.

were normal.

The patient had a preliminary diagnosis of infective endocarditis and was started on a treatment regimen consisting of ampicillin/sulbactam $4 \times 1 \mathrm{~g}$ /day and gentamicin 1x160 mg/day. Echocardiography examination showed normal left cardiac functions, valves and intact interatrial septum. Doppler ultrasound showed kidneys of normal size. Serologic tests were negative for antinuclear antibody, VDRL, rheumatoid factor, hepatitis B and C, HIV and brucella. Blood and urine cultures were also negative.

Patient was evaluated again because of sterile blood cultures and echocardiographic finding negative for infective endocarditis. Bilateral calf and upper limb claudicatio, Raynaud's phenomenon, polyarthralgia and skin pale on both her forearms were also reported throughout in the previous year. Because of widespread thoracic murmur and hypertension, contrast-enhanced thoracic magnetic resonance angiography was performed. Magnetic resonance angiography showed minimal flow in the left common carotid artery, no flow in the homolateral subclavian artery and narrowing of the aortic thoracic segment to $10.4 \mathrm{~mm}$ (Figure 2).

Based on these findings, the patient was diagnosed with TA. Treatment with prednisolone at a dose of 48 $\mathrm{mg} /$ day was initiated.

Discussion: Bacterial endocarditis may present itself with rheumatological symptoms in $28-42 \%$ of patients ${ }^{5}$ TA can be confused with infective endocarditis when ascending aorta and aortic valve are affected. As seen in our case, the widespread murmur occurring as a result of narrowing of the thoracic segment of aorta can mimic myocarditis or infective endocarditis. It must be kept in mind that, when the narrowing segment is limited to the distal part of the descending aorta, pulse difference may be absent. Some diseases complicating TA have been reported in the literature. TA can complicate Crohn's disease, systemic lupus erythematosus, rheumatoid arthritis, Wegener's granulomatosis and sarcoidosis..$^{6-8}$ In the literature, no data was found on the association of TA and infective endocarditis. Clinically similar signs can be present in the active disease state.

TA has several important complications that determine the prognosis, including secondary hypertension, aortic regurgitation, aneurysms and retinopathy. ${ }^{1,4}$ Among these complications, only hypertension was found in our patient and was 


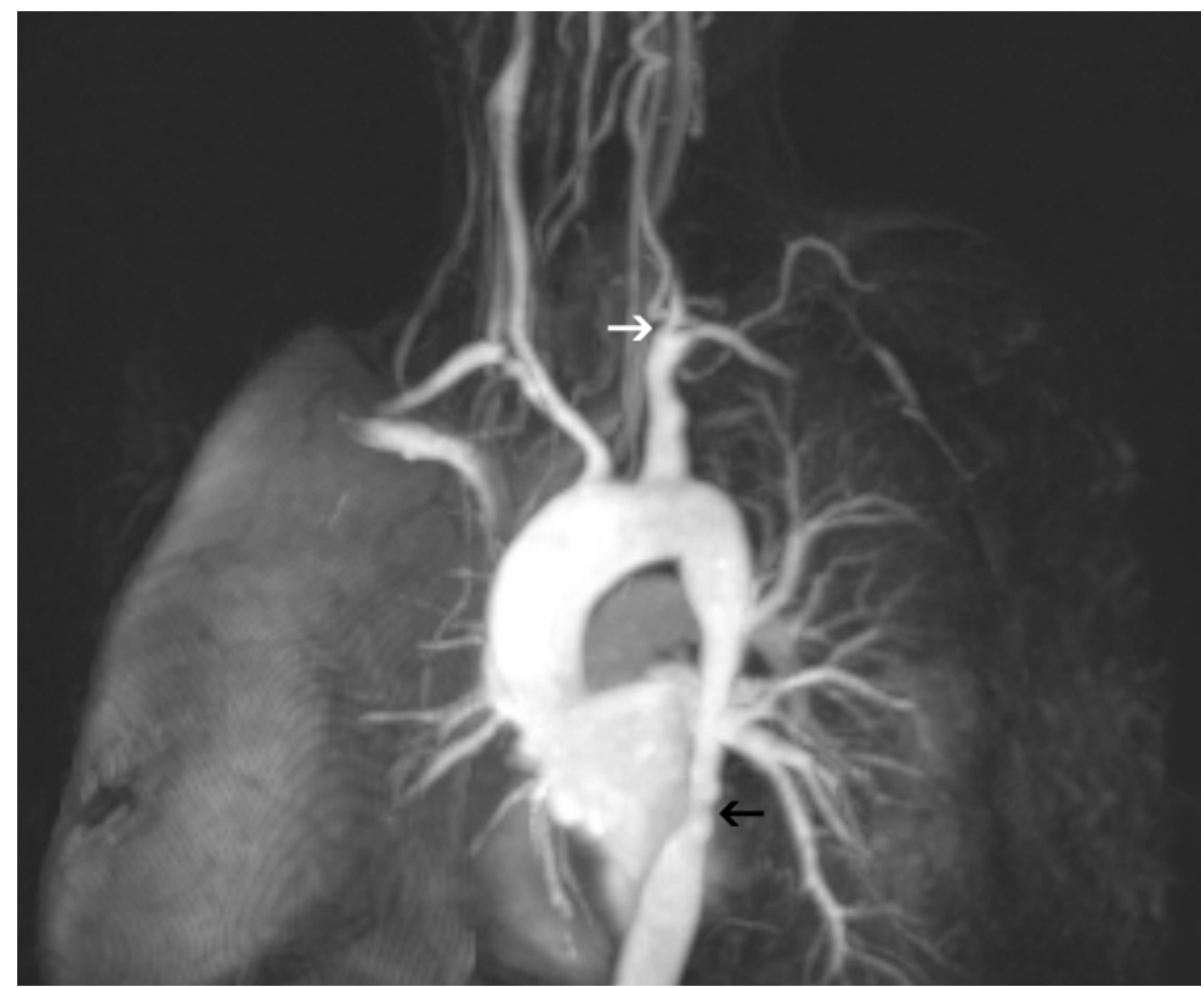

Figure 2. Magnetic resonance angiography showed minimal flow in the left common carotid artery (white arrow) and severe narrowing of the aortic thoracic segment (black arrow)

controlled well with $5 \mathrm{mg}$ amlodipine. Progress in medical technology has made the diagnose of TA easier. Computed tomography and magnetic resonance imaging can help to detect vascular diseases. ${ }^{9}$ In our case, MRI angiography was useful in evaluating the arterial involvement in TA. To diagnose TA accurately and as promptly as possible, and to evaluate the disease appropriately, the combined use of various imaging techniques is necessary.

\section{References:}

1. Park MC, Lee SW, Park YB, Chung NS, Lee SK. Clinical characteristics and outcomes of Takayasu's arteritis: analysis of 108 patients using standardized criteria for diagnosis, activity assessment, and angiographic classification. Scand J Rheumatol. 2005 Jul-Aug;34(4):284-92.

2. Slobodin G, Zeina AR, Rosner I, Boulman N, Rozenbaum M. Chronic pain of aortitis: an underestimated clinical sign? Joint Bone Spine 2008; 75: 96-8. PMid: 17981068

3. Bivilibal M, Duru N, Dogdu G, Elevli M, Ayta S. A Takayasu's Arteritis Case with Unilateral Digital Clubbing. Turk J Rheumatol 2011;26(2):163-166 http://dx.doi.org/10.5606/tjr.2011.025

4. Bicakcigil M, Aksu K, Kamali S, Ozbalkan Z, Ates A, Karadag O, Ozer HT, Seyahi E, Akar S, Onen F, Cefle A, Aydin SZ, Yilmaz N, Onat AM. Takayasu's arteritis in Turkey - clinical and angiographic features of 248 patients. Clin Exp Rheumatol. 2009 Jan-Feb;27(1 Suppl 52):S59-64.
Depending on the affected vessels, TA may present a wide variety of clinical symptoms. In TA, if the the distal part of the aorta is narrowed, widespread thoracic murmur can be found in the absence of a pulse difference. TA must be considered one of the underlying diseases that may cause widespread thoracic systolic murmur in young women with normal echocardiography.

5. Öztürk C, Özdedeli S, Çnar Y, Kayıkçıŏlu M. Infective endocarditis presenting as polymyalgia rheumatica: case report. $\begin{array}{llll}\text { Turk J 2011;26(2):154-157 } & \end{array}$ http://dx.doi.org/10.5606/tjr.2011.023

6. Weiler V, Redtenbacher S, Bancher C, Fischer MB, Smolen JS: Concurrence of sarcoidosis and aortitis: case report and review of the literature. Ann Rheum Dis 2000, 59:850-3. http://dx.doi.org/10.1136/ard.59.11.850 PMid:11053059 PMCid: 1753036

7. Wesemann D, Costenbader Kh, Coblyn J: Co-existing sarcoidosis, systemic lupus erythematosus and the antiphospholipid antibody syndrome: Case reports and discussion from the Brigham and woman?s hospital Lupus center. Lupus 2009, 18:202-5. http://dx.doi.org/10.1177/0961203308100483 PMid:19213857

8. Reny JL, Paul JF, Lefébvre C, Champion K, Emmerich J, Blétry E, Piette JC, Fiessinger JR: Association of Takayasu's arteritis and 
Crohn's disease. Results of a study on 44 Takayasu patients and review of the literature. Ann Med Int 2003, 154:85-90.

9. Taniguchi N, Itoh K, Honda M, Obayashi T, Nakamura M, Kawai

F, Irie T. Comparative ultrasonographic and angiographic study of

carotid arterial lesions in Takayasu's arteritis. Angiology 1997; 48

9-20 http://dx.doi.org/10.1177/000331979704800102 